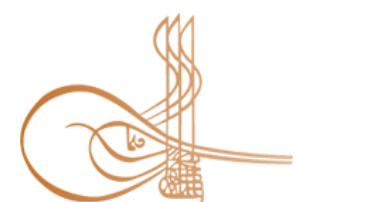

www.turkishstudies.net/economy
Turkish Studies - Economics, Finance, Politics

eISSN: 2667-5625

ResearchArticle / Arașttrma Makalesi

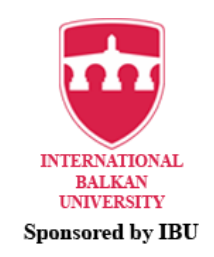

\title{
Küreselleşmenin Turizme Etkisi: OECD Ülkeleri Örneği
}

The Effect of Globalization on Tourism: The Case of OECD Countries

\author{
Gökhan Akar ${ }^{*}$ - Tufan Sarıtaş**
}

\begin{abstract}
With globalization and technological development every country in the world has been significantly affected economically and politically. The internationalization of cultures and investments has contributed to this situation with increasing competition and communication. Accordingly, the geographical expansion of connections between countries and the development of the transportation system have allowed easier and faster travel. In this context, tourism like many sectors has developed rapidly causing an important position for the economies of the country. The aim of this study is to investigate the impact of globalization on tourism through panel data analysis method for the 2000-2018 period in OECD Countries. Tourism has been represented by two different series: both tourism expenditures and tourism revenues. The DLT1 series, which represents international tourism spending in Model 1, is dependent on; general globalization DLKOF series, gross fixed capital formation DLGF1 series, real exchange rate DLEX series and DLG1 series representing GDP are independent series. In Model 2, the DLT3 series, which represents international tourism revenues, is dependent; general globalization DLKOF series, gross fixed capital formation DLGF1 series, real exchange rate DLEX series and DLG1 series representing GDP are independent series. In the findings for both models; it has been concluded that globalization positively affects both tourism spending and tourism receipts.
\end{abstract}

StructuredAbstract: Globalization leads to widespread use of economic integration, technology development, communication and transportation tools. It also allows countries to increase the opportunity to interact with each other. In this context, there are some changes and transformations in the world with the globalization process. In this connection, relations and interactions between countries are getting more and more intensified. Accordingly, an interaction process that reaches beyond borders in the fields of culture, education, politics and technology has become even more important. Technology, communication, tourism and capital have been mentioned globally, especially in the recent period with the concept of globalization. In this context, tourism sector, like many sectors, has developed rapidly around the world with the process of globalization. Depending on globalization, the widespread use of information communication technologies in tourism as well as in all sectors contributes positively to the sector. This development has provided

*Dr. Öğr. Üyesi, Karamanoğlu Mehmetbey Üniversitesi, İ.İ.B.F., İktisat Bölümü

Asst. Prof., Karamanoğlu Mehmetbey University, Faculty of Economics and Administrative Sciences, Department of Economics

ORCID 0000-0001-8401-4052

gakar@kmu.edu.tr

**Dr. Öğr. Üyesi, Karamanoğlu Mehmetbey Üniversitesi, İ.İ.B.F., İktisat Bölümü

Asst. Prof., Karamanoğlu Mehmetbey University, Faculty of Economics and Administrative Sciences, Department of Economics

ORCID 0000-0003-1728-2377

tufansaritas@kmu.edu.tr

Cite as/ Atıf: Akar, G. \& Sarıtaş, T. (2020). Küreselleşmenin turizme etkisi: OECD ülkeleri örneği. TurkishStudies -

Economy, 15(3), 1087-1102. https://dx.doi.org/10.47644/TurkishStudies.45461

Received/Geliş: 23 July/Temmuz2020

Checkedbyplagiarism software

Accepted/Kabul: 20 September/Eylül 2020

Published/Yayın: 25 September/Eylül 2020

Copyright (C) INTAC LTD, Turkey

CC BY-NC 4.0 
consumers with the opportunity to provide more information. In this context, the demand structure has gradually changed. This has led to increased competition in the tourism sector.

The main purpose of working in this direction is to examine the impact of the globalization process on tourism revenues and tourism expenditures. In this context, when the literature on the subject was examined, it was determined that there was a deficiency in empirical studies. In this context, the results obtained in the study are important for contributing to the literature. Accordingly, when the findings obtained in the studies in the literature are evaluated, it is seen that tourism and globalization can affect each other.

In this study, the impact of globalization on tourism for the period 2000-2018 in OECD Countries was investigated by panel data analysis method. Tourism has been represented by two different series both tourism expenditures and tourism receipts. Tourism expenditures in the first model and tourism receipts in the second model were defined as dependent series. All of the series used in the study were obtained from the World Bank and logarithmic transformation was applied to all of the series. In the study, cross section dependency tests were first applied to determine the presence of possible horizontal cross section dependence in models. With the Pesaran CIPS Unit Root Test, the stagnation of the series has been investigated. After that, non-static series in $\mathrm{I}(0)$ were taken differently and made static in $\mathrm{I}(1)$ and models were established. The F test was first applied to determine unit and/or time effects for the selection of appropriate econometric prediction models. The DLT1 series, which represents international tourism spending in Model 1, is dependent on; general globalization DLKOF series, gross fixed capital formation DLGF1 series, real exchange rate DLEX series and DLG1 series representing GDP are independent series. In Model 2, the DLT3 series, which represents international tourism revenues, is dependent; general globalization DLKOF series, gross fixed capital formation DLGF1 series, real exchange rate DLEX series and DLG1 series representing GDP are independent series. In both models; DLGF1 series representing gross fixed capital formation, DLEX series representing real exchange rate and DLG1 series representing GDP are control variables.

Peseran CD LM test was applied to determine possible horizontal section dependence in the models used in the study. The reason for applying this test is because the panel data set used in the research is $\mathrm{N}>\mathrm{T}$. It is understood that one-way time effective models are available for both models established in the study. Therefore, it was decided to use the Generalized Least Squares Method in both models. Because there are two versions of this method that can be used in both random and fixed effective models. In addition models can make consistent predictions even under the presence of heteroskedastic and autocorrelation problems. In the forecast results for model 1; globalization, tourism expenditures are seen to positively affect. In model 2 , it is seen that globalization also positively affects tourism receipts. In the findings for both models; it has been concluded that globalization positively affects both tourism spending and tourism receipts. According to the findings obtained in the study; an improvement in globalization factors is expected to contribute to the development of tourism for countries. In this context, policy needs to be developed to increase the globalization index in terms of the expected positive effects of tourism development. Because the increase in tourism receipts is considered the main target for any country's tourism sector. It is important to develop a tourism product suitable for the trends and changes of tourists in countries that are the main market for sustainable tourism. Therefore, tourism strategies for creating a tourism product supported by innovation should be implemented with a demandoriented approach. In this context, tourism product quality improvement and product differentiation plays an important role in this process. This will also contribute positively to the protection of competitiveness. In addition, new market research will positively affect the development of the tourism sector by creating price flexibility in the tourism product.

Keywords: Economics, Tourism, Globalization, Panel Data Analysis, OECD Countries.

Öz: Teknolojik gelişme ve küreselleşme süreciyle beraber dünyadaki her ülke ekonomik ve politik açıdan önemli düzeyde etkilenmiştir. Bu duruma artan rekabet ve iletişimle birlikte kültürlerin ve yatırımların uluslararasılaşması katkı sağlamıştır. $\mathrm{Bu}$ doğrultuda ülkeler arasındaki bağlantıların coğrafi olarak genişlemesi ve ulaşım sisteminin gelişmesi daha kolay ve hızlı seyahat etme imkanı tanımıştır. Bu kapsamda turizmin, birçok sektör gibi hızlı bir gelişme göstermesi ülke ekonomileri açısından önemli bir konuma sahip olmasına neden olmuştur. Bu çalışmanın amacı OECD Ülkelerinde 2000-2018 periyodu için küreselleşmenin, turizm üzerindeki etkisini panel veri analiz yöntemiyle araştırmaktır. Turizm hem turizm harcamaları hem de turizm gelirleri olmak üzere iki farklı seri ile temsil edilmiștir. Model 1'de uluslararası turizm harcamalarını temsil eden $D L T 1$ serisi bağımlı; genel küreselleşmeyi temsil eden $D L K O F$ serisi, brüt

Turkish Studies - Economy, 15(3) 
sabit sermaye oluşumunu temsil eden $D L G F 1$ serisi, reel döviz kurunu temsil eden $D L E X$ serisi ve GSYIH'yi temsil eden $D L G 1$ serisi bağımsız serilerdir. Model 2'de ise, uluslararası turizm gelirlerini temsil eden $D L T 3$ serisi bağımlı; genel küreselleşmeyi temsil eden DLKOF serisi, brüt sabit sermaye oluşumunu temsil eden $D L G F 1$ serisi, reel döviz kurunu temsil eden $D L E X$ serisi ve GSYIH'yi temsil eden $D L G 1$ serisi bağımsız serilerdir. Her iki model için de elde edilen bulgularda; küreselleşmenin hem turizm harcamalarını hem de turizm gelirlerini pozitif yönlü olarak etkilediği sonucuna ulaşılmıştır.

Anahtar Kelimeler: İktisat, Turizm, Küreselleşme, Panel Veri Analizi, OECD Ülkeleri

\section{Giriş}

Dünyadaki ekonomilerin, özellikle ticaret ve finansal akışlar yoluyla artan entegrasyonu olarak ifade edilen küreselleşme insani yeniliklerin ve teknolojik ilerlemenin sonucu olan tarihsel bir süreçtir. Bu kapsamda geniş kültürel, politik ve çevresel boyutları da bulunan küreselleşme, insanların ve bilginin uluslararası sınırlar üzerindeki hareketini de ifade etmektedir (IMF, 2000). Küreselleşme, ekonomik entegrasyon, teknoloji devrimi, iletişim ve ulaşım araçlarının yaygın kullanımı ve uluslar için birbirleriyle etkileşime girme firsatlarının artmasına neden olurken, kültürel farklı1ıkları azaltarak diğer birçok konu açısından dünyayı küçük bir boyuta dönüştürmektedir (Mustafa, 2010:37).

Küreselleşme süreciyle birlikte dünyada bir takım değişim ve dönüşümler yaşanmaktadır. $\mathrm{Bu}$ bağlamda ülkeler arasındaki ilişkiler ve etkileşimler giderek yoğunlaşmaktadır. Bu doğrultuda kültür, hukuk, eğitim, siyaset ve teknoloji alanlarında sınırların ötesine ulaşan bir etkileşim süreci daha da önemli hale gelmiştir. Özellikle son dönemde küreselleşme kavramıyla birlikte teknoloji, iletişim, turizm ve sermaye gibi kavramlar küresel boyutta ifade edilmeye başlanmıştır. Bu kapsamda birçok sektör gibi turizm sektörü de küreselleşme süreciyle beraber dünya genelinde hızlı bir gelişme göstermiştir (Çeken vd., 2008). Bununla birlikte bir kalkınma stratejisi olarak turizmin önemi ihracat ve ekonomik büyüme arasındaki ilişkiden kaynaklanmaktadır. Bu bağlamda nakliye maliyetleri veya sigorta masraflarının olmaması gibi nedenlerden dolayı yerel olarak üretilen ürünler, turistlere daha yüksek bir karla satılabilmektedir. Ayrıca ülkelerin uluslararası pazarlama uzmanlığının yetersiz düzeyde olması veya ihracat kabiliyetinin tam olarak geliştirilememesi gibi nedenlerden dolayı uluslararası piyasada pazar anlamında sorun yaşayan malların turistlere satılması mümkün olabilmektedir (Croes, 2006).

Küreselleşme sürecinin hız kazanması sonucunda ülkeler arasındaki coğrafi sınırların kalkması, farklı kültürlere sahip insanların birbirlerini tanıması kolaylaşmıştır. Bu kapsamda dünya genelinde insanların ortak dilleri kullanması ve kültürel etkileşimde bulunmaları turizm sektörünün gelişmesine neden olmaktadır. Küreselleşme süreciyle birlikte daha da önemli hale gelen küresel rekabet ortamı, turizm alanında değişim ve dönüşümü bir zorunluluk haline getirerek hem ulusal hem de uluslararası turizmde daha kaliteli hizmet sunulması ile sürdürülebilir rekabet gücü elde etmeyi zorunlu k1lmıştır (Çeken \& Ateşoğlu, 2008:139).

Turizm, ülke ekonomileri açısından oluşturmuş olduğu ekonomik ve politik etkileri nedeniyle sadece turizm hareketlerinden önemli pay alan gelişmiş ülkeler için değil, aynı zamanda gelişmekte olan ülkeler içinde önemli hale gelmiştir. Bu bağlamda uluslararası arenada ulaşmış olduğu konumla birlikte turizm, ekonomik, sosyal ve kültürel hayatı etkileyebilecek bir yapıya kavuşmuştur. Ayrıca siyasal bakımdan da önemli toplumsal fonksiyonların gerçekleştirilmesini kolaylaştırabilecek bir role sahip olması nedeniyle de turizm, ülke ekonomileri açısından önem verilmesi gereken bir alan olarak karşımıza çıkmaktadır (Bulut, 2000).

$\mathrm{Bu}$ doğrultuda çalışmanın temel amacı küreselleşme sürecinin turizm gelirleri ve turizm harcamaları üzerindeki etkisini incelemektir. $\mathrm{Bu}$ çalışmanın geri kalanı aşağıdaki gibi düzenlenmiştir. İkinci bölümde literatür incelemesi yapılmıştır. Üçüncü bölümde yöntem ve 
çalışmada kullanılan veriler açıklanmıştır. Daha sonra ise sırasıyla analiz sonuçları ile sonuç kısmına yer verilmiştir.

\section{Literatür Taraması}

Küreselleşme, yerler arasındaki bağlantıların mekansal bir şekilde genişlemesine, kültürlerin uluslararalılaşmasına, rekabet artışına, daha fazla küresel ürün ve hizmet akışına yol açmak şeklinde açıklanabilmektedir. Küreselleşme olgusu dünya çapında faaliyetlerin genişletilmesi olarak görülmektedir. $\mathrm{Bu}$ durum eğlence ve kültür açısından turizmin uluslararasılaşmasını sağlayarak, artan rekabetle birlikte turistlerin daha fazla küresel akışına neden olmaktadır. Bu doğrultuda yerler arasındaki bağlantıların coğrafi olarak genişlemesi, uluslararası turizmin gelişmesinde önemli bir faktör haline gelmiştir (Mpofu, 2009).

Küreselleşme sürecinde önemli bir güç olan turizm, uzak hedeflerin kolayca ve hızlı bir şekilde erişilebilir hale geldiği modern ulaşım sisteminin oluşturulmasına katkı sağlamıştır. Bu kapsamda küreselleşme, turizmin küresel olarak büyümesine ve batılı olmayan dünyaya yayılmasına önemli bir ivme kazandırmıştır. Ayrıca küreselleşmeyle birlikte gelişen turizm, yapısında yeni faktörlerin girişiyle önemli değişiklikler geçirmiştir (Cohen, 2012). Siyasi ve yasal açıdan yaşanan bu değişiklikler, ticaret özgürlüğünü, turizmde ulaşımın serbestleştirilmesini ve gelișen sistemlerle birlikte uluslararası yatırımların daha esnek ve uyarlanabilir olmasına olanak tanımıştır. Bu durum emek hareketliliğini kolaylaştırırken insanların sistemleri yönetmek için farklı ülkelere seyahat etmelerine de imkan tanımıştır (Hociung\& Francu,2012:134-135). Bu kapsamda uluslararası seyahatin basitleşmesi yabancı sermaye yatırımlarının artmasına neden olurken, turizm sektöründeki yatırımlarla birlikte turizm bilincinin gelișmesini sağlamıștır. Bu durum seyahat işlemlerini asgari düzeye indirerek uluslararası turizmin gelişimini pozitif yönde etkilemiştir (Çeken vd.,2008). Ayrıca küreselleşmenin artmasıyla birlikte riski uluslararası olarak çeşitlendirme fırsatı ortaya çıkmış ve daha yüksek getiri oranları arayan yatırımların artması mümkün olmuştur. Aynı zamanda, birçok ülke, sermaye çıkışları üzerindeki kısıtlamaları ortadan kaldırarak veya daha esnek hale getirerek, doğrudan yabancı yatırımlara getirilen kısıtlamaların serbestleşmesiyle birlikte piyasaya yönelik reformlar sayesinde ekonomik beklentilerini geliştirerek sermaye girişlerini teşvik etmiştir (Agenor, 2003:1089). Bu durum turizm sektörü için gerekli olan yatırımların gerçekleşmesi açısından önemli bir rol oynamıştır.

Turizm, seyahat ve konaklama endüstrileri üzerinde küreselleşmenin itici güç olma özelliği taşıyan bazı yönleri vardır (Mustafa, 2010). Ulaşım sektörü bunlardan biri olarak kabul edilmektedir. Özellikle hava taşımacılı̆̆ 1 alanı, turizmin gelişmesinde kilit bir belirleyicidir. Geleneksel olarak ikili düzeyde sürdürülen hava taşımacılığının serbestleştirilmesiyle birlikte günümüzde çok taraflı ticaret anlaşmaları özelliği göstermektedir. Bu kapsamda hava hizmetlerinin serbestleşmesi düşük maliyetli hizmetlerin gelişimini de artırmıştır (ILO, 2001). Ayrıca küreselleşmeyle birlikte özellikle ulaşım araçlarındaki ortaya çıkan hız, konfor, kapasite gibi faktörlerde yaşanan gelişmeler seyahat sektörünün ilerlemesine pozitif katkı sağlamıştır (Buluk \& Özkök, 2016).

Küreselleşme, insanların farklı kültürleri tanıma imkânını artırarak kültürlerarası etkileşime katkı sağlamıştır. Bu kapsamda insanların farklı kültürleri tanıma isteklerindeki artışla birlikte kültür turizminin önemi de giderek artmıştır. Bu doğrultuda küresel çapta şekillenen sosyal etkenler de, insanları turizme yönlendirmektedir (Çeken vd., 2009:31). Örneğin, bir ülke, küresel ekonomi ve topluma daha fazla entegre olduğunda daha fazla uluslararası turist çekebilmesi muhtemeldir. Bu bağlamda bir ülke diğer ülkelerle olumlu siyasi ilișkiler kurduğunda, dini ve diğer iç çatıșmaları çözmeye çalıştı̆̆ında, uluslararası kuruluşlara aktif olarak katıldığı ve yabancı elçiliklerin sayısını artırdığı zaman, ülkeye daha fazla turistin gelmesi mümkün olabilmektedir (Fereidouni vd., 2014:365). 
Bilgi iletişim teknolojileri de küreselleşmeyle birlikte tüm sektörlerde olduğu gibi turizmde de yaygın olarak kullanılması sektöre olumlu katkı sağlamaktadır. Çünkü turizm sektörü turistik talebin bilgiye olan ihtiyacının fazla olması nedeniyle bilgi iletişim teknolojilerinin en yoğun şekilde kullanıldığı sektörler arasında yer almaktadır (Kuşat, 2011:120). Bu kapsamda küreselleşme süreciyle birlikte turizm sektöründe bilgisayarlı rezervasyon sistemleri, global dağıtım sistemleri, telekonferanslar, video broşürleri, yönetim bilgi sistemleri, havalimanı elektronik bilgi sistemleri, dijital telefon cihazlan, mobil iletişim araçlan, internet ve tüm telekomünikasyon hizmetlerin de büyük bir gelişme yaşanmıştır. Bu gelişme, tüketicilere daha fazla bilgi sunma firsatı sağlamıştır. Bu kapsamda talep yapısı giderek artan bir şekilde farklılaşarak değişmiştir. $\mathrm{Bu}$ durum turizm sektöründeki rekabetin artmasına neden olmuştur (Bahar, 2007:64).

$\mathrm{Bu}$ kapsamda turizm konusu birçok araştırmacı tarafından farklı analiz yöntemleri kullanılarak incelenmiştir. İlgili literatür incelendiğinde araştırmaların yoğunluğunun ekonomik büyüme ve turizm ilişkisini ele alan çalışmalarda olduğu görülmektedir (Dritsakis, 2004; Khalil vd., 2007; Fayissa, 2008; Kızılgöl \& Erbaykal, 2008; Elias \& Proenca, 2008; Katircioglu, 2009; Sarmidi \& Salleh, 2010; Hepektan \& Çınar, 2010; Massidda \& Mattana, 2013; Kanca, 2015; Kızılkaya vd., 2016; Saraç vd., 2018; Gövdeli, 2018; Ayaydın vd., 2019; Gövdeli, 2019). Ayrıca turizm ve uluslararası ticaret arasındaki ilişkiyi inceleyen çalışmalarda bulunmaktadır (Kulenderan \& Wilson, 2000; Shan \& Wilson, 2001; Luzzi \& Fluckiger, 2003; Khan vd.,2005; HernándezMartín, 2007; Bahar \& Baldemir, 2008; Fischer \& Gil-Alana, 2009; Cattaneo, 2009; Fry vd., 2010; Kadir \& Jusoff, 2010; Gautam \& KG, 2012; Santana-Gallego, vd., 2011; Özcan, 2016; El-Sahli, 2018; Ongan \& Göçer, 2020). Bazı araştırmacılar turizmin cari işlemler dengesi üzerindeki etkisini incelerken (Alagöz \& Erdoğan, 2008; Bozgeyik \& Eban, 2017; Yapar Saçık, vd., 2019) bazı çalışmalar da turizm ve doğrudan yabancı yatırımlar arasındaki ilişki ele alınmıştır (Peric \& Radic, 2016; Rajapakse, 2016; Yazdi, vd., 2017; Bezic \& Radic, 2017; Chen, 2017; Yu-Chi \& Lin, 2018; Satrovic \& Muslija,2019). Bu kapsamda küreselleşme ve turizm arasındaki ilişkiyi inceleyen sınırlı sayıda çalışma bulunmaktadır. Bu çalışmalardan bazıları aşağıda gibi özetlenmiştir.

Fereidouni vd. (2014) tarafindan yapılan çalışmada 1995-2008 dönemine ait verileri kullanarak Orta Doğu ve Kuzey Afrika bölgesinde küreselleşme ve turizm arasındaki kısa ve uzun dönemli ilişkiyi panel veri yöntemiyle incelemişlerdir. Çalışmanın sonucuna göre turizmin küreselleşmeyi destekleyebileceği ve küresel ekonomi ve toplumsal entegrasyonun kısa ve uzun dönemde turist gelişlerini teşvik ettiği sonucuna ulaşmışlardır.

Javid ve Katırcığlu (2017) tarafından yapılan çalışmada ekonomik, sosyal ve politik küreselleşme göstergelerinin turizm gelişimi üzerindeki etkisini 133 ülke için 1995-2014 dönemine ait verileri kullanarak panel veri yöntemiyle incelemişlerdir. Çalışmada küreselleşmenin turizm gelişimi için önemli bir faktör olduğu sonucuna ulaşmışlardır.

Çalışmalarda elde edilen bulgular genel olarak değerlendirildiğinde turizm ve küreselleşme değişkenlerinin birbirini etkileyebileceği görülmektedir. $\mathrm{Bu}$ çalışmada değişkenler arasındaki ilişkinin, örneklem ve uygulanan yöntem açısından farklılık arz etmesi nedeniyle araştırmanın literatüre katkı sağlayacağı düşünülmektedir.

\section{Veri ve Yöntem}

Bu çalışmada OECD Ülkelerinde 2000-2018 periyodu için küreselleşmenin, turizm üzerindeki etkisi panel veri analiz yöntemiyle araştırılmıştır. Turizm hem turizm harcamaları hem de turizm gelirleri olmak üzere iki farklı seri ile temsil edilmiştir. Birinci modelde turizm harcamaları, ikinci modelde ise turizm gelirleri bağımlı birer seri olarak tanımlanmıştır. Çalışmada kullanılan seriler ve elde edildikleri kaynaklar, aşağıdaki tabloda gösterilmektedir. 
Tablo 1: Serilere İlişskin Bilgiler

\begin{tabular}{ccc}
\hline Değişken Adı & Değişkenin Tanımı & Kaynak \\
\hline DLT1 & UluslararasıTurizmHarcamaları (Dolar) & Dünya Bankası \\
DLT3 & Uluslararası Turizm Gelirleri (Dolar) & Dünya Bankası \\
DLKOF & KOF Genel Küreselleşme Endeksi & Dünya Bankası \\
DLGF1 & GSYİH’nin Yüzdesi Olarak Brüt Sabit Sermaye & Dünya Bankası \\
DLEX & Reel döviz Kuru & Dünya Bankası \\
DLG1 & 2010 Fiyatlarıla Dolar Bazında GSYİH & Dünya Bankası \\
\hline
\end{tabular}

Çalışmada kullanılan serilerin tümü Dünya Bankası'ndan elde edilmiş ve yine serilerin tümüne logaritmik dönüşüm uygulanmıştır. Serilere ilişkin tanımlayıcı istatistikler ise aşağıdaki tabloda raporlanmıştır.

Tablo 2: Serilere İlişkin Tanımlayıcı İstatistikler

\begin{tabular}{ccccccc}
\hline Değişken & Ortalama & & Min. & Maks. & Standart Hata & Gözlem \\
\cline { 5 - 6 } DLT1 & 0.050 & -0.725 & 1.882 & 0.156 & 792 \\
DLT3 & 0.055 & & -0.632 & 1.832 & 0.148 & 792 \\
DLKOF & 0.008 & -0.049 & 0.096 & 0.014 & 792 \\
DLGF1 & -0.014 & -10.450 & 11.572 & 1.688 & 792 \\
DLEX & -0.006 & -0.353 & 0.304 & 0.088 & 792 \\
DLG1 & 0.027 & -0.160 & 0.224 & 0.031 & 792 \\
\hline
\end{tabular}

Ekonometride üç tip veri seti kullanılmaktadır. Bunlar; zaman serisi verileri, kesit veriler ve panel veriler (Gujarati \& Porter, 2012:22). Bu çalışmada kullanılan veri seti, panel veri seti olduğundan, analiz yöntemi olarak, panel veri analizi tercih edilmiştir. Bilindiği gibi panel veri seti, her bir yatay kesit için bir zaman serisi içerir (Wooldridge, 2013:10). Dolayısıyla da hem zaman serileri hem de kesit verilerle yapılan çalışmalara göre daha kapsamlı analizlerin yapılmasına imkân tanır.

Çalışmada, modellerdeki olası yatay kesit bağımlılığının varlığını saptamak için öncelikle yatak kesit bağımlılığı testlerine başvurulmuştur. Araştırmada kullanılan veri seti $\mathrm{N}>\mathrm{T}$ şeklinde olduğundan, $\mathrm{N}>\mathrm{T}$ durumunda Peseran (2004) tarafindan kullanılması tavsiye edilen Peseran CD LM Testi tercih edilmiştir. Yatay kesit bağımlılığı testine başvurulmasının nedeni, modellerdeki yatay kesit bağımlılı̆̆ının varlı̆̆ durumunda, yatay kesit bağımlılı̆̆ altında bile tutarlı tahmin yapabilen ikinci nesil birim kök testlerinin tercih edilip edilmemesine karar verebilmektir. Peseran CD LM Testine ait prob. değerinin, istatistiksel olarak \%5 anlamlılık seviyesinden küçük olması durumunda, yatay kesit bağımlılı̆̆ının bulunmadığını ifade eden $\mathrm{H}_{0}$ hipotezi reddedilir ve yatay kesit bağımlılığının bulunduğunu ifade eden $\mathrm{H}_{1}$ hipotezi kabul edilir. Bunun aksine prob. değerinin, istatistiksel olarak \%5 anlamlılık seviyesinden büyük olması durumunda ise yatay kesit bağımlılığının bulunmadığını ifade eden $\mathrm{H}_{0}$ hipotezi kabul edilir ve yatay kesit bağımlılığının bulunduğunu ifade eden $\mathrm{H}_{1}$ hipotezi reddedilir. 
Kurulan modellerde yatay kesit bağımlılı̆̆1 söz konusu olduğundan, ikinci nesil birim kök testlerinden; Pesaran (2007) tarafından önerilen Pesaran CIPS Birim Kök Testi ile serilere ilişkin durağanlıklar araştırılmıştır. Bundan sonra ise $I(0)$ 'da durağan olmayan seriler, birinci farkları alınarakI(1)'de durağan hale getirilmiş ve modeller kurulmuştur.

Oluşturulan modellere uygun ekonometrik tahmin modellerinin seçimi için ilk olarak birim ve/veya zaman etkilerin tespit edilmesi amaciyla $\mathrm{F}$ Testine başvurulmuştur. Birim etkiye yönelik $\mathrm{F}$ Testi prob. değerinin, istatistiksel olarak $\% 5$ anlamlılık seviyesinden küçük olması durumunda, birim etkilerin bulunmadığını ifade eden $H_{0}$ hipotezi reddedilir ve birim etkilerin bulunduğunu ifade eden $H_{l}$ hipotezi kabul edilir. Aynı şekilde zaman etkiye yönelik F Testi prob. değerinin, istatistiksel olarak $\% 5$ anlamlılık seviyesinden küçük olması durumunda, zaman etkilerin bulunmadığını ifade eden $\mathrm{H}_{0}$ hipotezi reddedilir ve zaman etkilerin bulunduğunu ifade eden $\mathrm{H}_{1}$ hipotezi kabul edilir (Yerdelen Tatoğlu, 2018:168-171).

Modellerdeki rassal ve sabit etkilerin saptanması için de Hausman (1978) Testi kullanılmıştır. Hausman Testine ait prob. değerinin, istatistiksel olarak \%5 anlamlılık seviyesinden küçük olması durumunda sabit etkiler modelinin geçerli olduğu, buna karşıllk prob. değerinin istatistiksel olarak $\% 5$ anlamlllık seviyesinden büyük olması durumunda ise rassal etkiler modelinin geçerli olduğu kabul edilir. Çalışmada kullanılan iki model şu şekildedir:

$$
\begin{aligned}
& D L T 1_{i t}=\beta_{0}+\beta_{1} D L K O F+\beta_{2} D L G F 1+\beta_{3} D L E X+\beta_{4} D L G 1+\varepsilon_{i t}(1) \\
& D L T 3_{i t}=\beta_{0}+\beta_{1} D L K O F+\beta_{2} D L G F 1+\beta_{3} D L E X+\beta_{4} D L G 1+\varepsilon_{i t}
\end{aligned}
$$

Model 1'de uluslararası turizm harcamalarını temsil eden DLT1 serisi bağımlı; genel küreselleşmeyi temsil eden $D L K O F$ serisi, brüt sabit sermaye oluşumunu temsil eden $D L G F 1$ serisi, reel döviz kurunu temsil eden $D L E X$ serisi ve GSYİH'yi temsil eden $D L G 1$ serisi ise bağımsız serilerdir. Model 2'de ise, uluslararası turizm gelirlerini temsil eden DLT3 serisi bağımlı; genel küreselleşmeyi temsil eden $D L K O F$ serisi, brüt sabit sermaye oluşumunu temsil eden $D L G F 1$ serisi, reel döviz kurunu temsil eden $D L E X$ serisi ve GSYIH'yi temsil eden $D L G 1$ serisi ise bağımsız serilerdir. Ayrıca her iki modelde de brüt sabit sermaye oluşumunu temsil eden $D L G F 1$ serisi, reel döviz kurunu temsil eden DLEX serisi ve GSYIH'yi temsil eden $D L G 1$ serisi, kontrol değiş̧kenleridir. Bu üç kontrol değişkeni, Javid ve Katırcıoğlu (2017) tarafindan yapılan ve turizm küreselleşme ilişkisinin incelendiği araştırma baz alınarak seçilmiştir.

Çalışmada modellerin tahmininde Genelleştirilmiş En Küçük Kareler Yöntemi kullanılmıştır. Bilindiği gibi bu yöntem hem rassal hem de sabit etkili modellerde kullanılabilmekte ve ayrıca buna ek olarak modellerde heteroskedasite ve otokorelasyon problemlerinin varlığ altında bile tutarlı tahmin yapabilmektedir (Yerdelen Tatoğlu, 2018:101).

\section{Analiz Sonuçları}

Çalışmada ilk olarak kullanılan modellerde olası yatay kesit bağımlılığının tespiti için Peseran CD LM Testine başvurulmuştur. Bu teste başvurulmasının nedeni, araştırmada kullanılan panel veri setinin $\mathrm{N}>\mathrm{T}$ şeklinde olmasıdır.

Tablo 3: Peseran CD LM Testi Sonuçları

\begin{tabular}{ccc}
\hline & Model-1 & Model-2 \\
\hline $\begin{array}{c}\text { Katsayı } \\
\text { (Prob.) }\end{array}$ & 4.143 & 11.750 \\
$(0.000)$ & $(0.000)$ \\
\hline
\end{tabular}

www.turkishstudies.net/economy 
Yukarıdaki tabloda Pesaran CD LM Testi sonuçları gösterilmektedir. Her iki model için de prob. değerlerinin istatistiksel olarak \%5 anlamlılık seviyesinden küçük olması, yatay kesit bağımlılığının bulunmadığını ifade eden $H_{0}$ hipotezinin reddedilerek, yatay kesit bağımlılığının bulunduğunu ifade eden $H_{l}$ hipotezinin kabul edilmesi gerektiğini ifade etmektedir. Dolayısıyla her iki modelde de yatay kesit bağımlılı̆̆ının bulunduğu anlaşılmaktadır. Bu nedenle serilere ilişkin durağanlıkların tespitinde, yatay kesit bağımlılı̆̆ının varlığında bile tutarlı tahminlerde bulunabilen ikinci nesil birim kök testlerinden Pesaran CIPS Birim Kök Testine başvurulmuş ve ilgili teste ait sonuçlar aşağıdaki tabloda raporlanmıştır.

Tablo4: Peseran CIPS Birim Kök Testi Sonuçları

\begin{tabular}{|c|c|c|c|c|c|}
\hline \multirow{2}{*}{ Değişken } & \multirow{2}{*}{ Model } & \multirow{2}{*}{ Test İst. } & \multicolumn{3}{|c|}{ Kritik Eşikler } \\
\hline & & & $\% 10$ & $\% 5$ & $\% 1$ \\
\hline \multirow[b]{2}{*}{ DLT1 } & Sabit & -2.238 & -2.08 & -2.16 & -2.30 \\
\hline & $\begin{array}{c}\text { Sabit } \\
\text { Trendli }\end{array}$ & -2.451 & -2.58 & -2.65 & -2.78 \\
\hline \multirow[b]{2}{*}{$\Delta$ DLT1 } & Sabit & -4.068 & -2.08 & -2.16 & -2.30 \\
\hline & $\begin{array}{c}\text { Sabit } \\
\text { Trendli }\end{array}$ & -4.195 & -2.58 & -2.65 & -2.78 \\
\hline \multirow[b]{2}{*}{ DLT3 } & Sabit & -2.107 & -2.08 & -2.16 & -2.30 \\
\hline & $\begin{array}{c}\text { Sabit } \\
\text { Trendli }\end{array}$ & -2.255 & -2.58 & -2.65 & -2.78 \\
\hline \multirow[b]{2}{*}{$\triangle \mathrm{DLT3}$} & Sabit & -4.251 & -2.08 & -2.16 & -2.30 \\
\hline & $\begin{array}{c}\text { Sabit } \\
\text { Trendli }\end{array}$ & -4.308 & -2.58 & -2.65 & -2.78 \\
\hline \multirow[b]{2}{*}{ DLKOF } & Sabit & -2.099 & -2.08 & -2.16 & -2.30 \\
\hline & $\begin{array}{c}\text { Sabit } \\
\text { Trendli }\end{array}$ & -2.655 & -2.58 & -2.65 & -2.78 \\
\hline \multirow[b]{2}{*}{$\triangle D L K O F$} & Sabit & -4.532 & -2.08 & -2.16 & -2.30 \\
\hline & $\begin{array}{c}\text { Sabit } \\
\text { Trendli }\end{array}$ & -4.704 & -2.58 & -2.65 & -2.78 \\
\hline \multirow[b]{2}{*}{ DLGF1 } & Sabit & -1.857 & -2.08 & -2.16 & -2.30 \\
\hline & $\begin{array}{c}\text { Sabit } \\
\text { Trendli }\end{array}$ & -2.158 & -2.58 & -2.65 & -2.78 \\
\hline \multirow[b]{2}{*}{$\triangle$ DLGF1 } & Sabit & -3.808 & -2.08 & -2.16 & -2.30 \\
\hline & $\begin{array}{c}\text { Sabit } \\
\text { Trendli }\end{array}$ & -3.943 & -2.58 & -2.65 & -2.78 \\
\hline \multirow[b]{2}{*}{ DLEX } & Sabit & -1.995 & -2.08 & -2.16 & -2.30 \\
\hline & $\begin{array}{c}\text { Sabit } \\
\text { Trendli } \\
\end{array}$ & -2.340 & -2.58 & -2.65 & -2.78 \\
\hline \multirow[b]{2}{*}{$\triangle D L E X$} & Sabit & -4.036 & -2.08 & -2.16 & -2.30 \\
\hline & $\begin{array}{c}\text { Sabit } \\
\text { Trendli }\end{array}$ & -4.235 & -2.58 & -2.65 & -2.78 \\
\hline \multirow[b]{2}{*}{ DLG1 } & Sabit & -1.508 & -2.08 & -2.16 & -2.30 \\
\hline & $\begin{array}{c}\text { Sabit } \\
\text { Trendli }\end{array}$ & -2.073 & -2.58 & -2.65 & -2.78 \\
\hline \multirow[b]{2}{*}{$\Delta \mathbf{D L G 1}$} & Sabit & -3.224 & -2.08 & -2.16 & -2.30 \\
\hline & $\begin{array}{c}\text { Sabit } \\
\text { Trendli }\end{array}$ & -3.241 & -2.58 & -2.65 & -2.78 \\
\hline
\end{tabular}


Yukarıda Peseran CIPS Birim Kök Testine ilişkin elde edilen bulgularda, serilerin tümünün $I(0)$ 'da durağan olmadığı ve $I(1)$ 'de durağan olduğu anlaşılmaktadır. Dolayısıyla da serilerin tümü, birinci farkları alınarak, $I(I)$ 'de durağan hale getirilmiş ve modeller oluşturulmuştur. Bundan sonra ise; modellerdeki birim ve/veya zaman etkilerin saptanması için $\mathrm{F}$ testine başvurulmuş ve bulgular, aşağıdaki tabloda raporlanmıştır.

Tablo 5: Birim ve/veya Zaman Etkilerin Saptanmasına Yönelik F Testi Sonuçları

\begin{tabular}{ccc}
\hline & Model 1 & Model 2 \\
\hline Birim Etki & 0.4300 & 0.6000 \\
& $(0.9985)$ & $(0.9688)$ \\
Zaman Etki & 2.1800 & 3.7800 \\
& $(0.0017)$ & $(0.0000)$ \\
\hline \multirow{2}{*}{ Uygun Model } & Tek Yönlü Zaman Etkiler & Tek Yönlü Zaman Etkiler \\
\hline
\end{tabular}

F Testi sonuçlarında görüldüğü üzere her iki modelde de birim etkilere ait $\mathrm{F}$ Testi prob. değerlerinin istatistiksel olarak $\% 5$ anlamlılık seviyesinden düşük olduğu anlaşılmaktadır. Bir diğer deyișle, birim etkilerin bulunmadığını ifade eden $H_{0}$ hipotezi kabul edilerek, birim etkilerin bulunduğunu ifade eden $H_{l}$ hipotezi ise reddedilir. Buna karşın her iki modelde zaman etkilere ait $\mathrm{F}$ Testi prob. değerlerinin istatistiksel olarak $\% 5$ anlamlılık seviyesinden düşük olduğu görülmektedir. Yani zaman etkilerin bulunmadığını ifade eden $H_{0}$ hipotezi reddedilerek, zaman etkilerin bulunduğunu ifade eden $H_{l}$ hipotezi kabul edilir. Dolayısıyla modellerde birim ve zaman etkilerin birlikte bulunduğu iki yönlü modellerin kullanılabilir olmadığı, tek yönlü zaman etkiler modellerinin geçerli olduğu anlaşılmaktadır.

Çalışmada kurulan her iki model için de tek yönlü zaman etkili modellerin kullanılabilir olduğu anlaşıldıktan sonra Genelleştirilmiş En Küçük Kareler Yöntemi'nin her iki modelde de kullanılmasına karar verilmiştir. Çünkü bu yöntemin hem rassal hem de sabit etkili modellerde kullanılabilir iki versiyonu bulunmakta ve ayrıca buna ek olarak modellerde heteroskedasite ve otokorelasyon problemlerinin varlığı altında bile tutarlı tahmin yapabilmektedir. Modellere ilişkin Genelleştirilmiş En Küçük Kareler Yöntemi ile yapılan tahmin sonuçları aşağıdaki tabloda raporlanmıştır. 
Tablo 6: Genelleştirilmiş En Küçük Kareler Yöntemi Tahmin Sonuçları

Model1

\begin{tabular}{ccc}
\hline & Bă̆ımlı Değişken: DLT1 & Bă̆ımlı Değişsen: DLT3 \\
\hline DLKOF & $1.4680^{*}$ & $2.1643^{*}$ \\
& $(0.0000)$ & $(0.0000)$ \\
DLGF1 & $0.0118^{*}$ & $0.0092^{*}$ \\
& $(0.0000)$ & $(0.0060)$ \\
DLEX & $0.9056^{*}$ & $0.6073^{*}$ \\
& $(0.0000)$ & $(0.0000)$ \\
DLG1 & $0.6064^{*}$ & $0.4244^{*}$ \\
& $(0.0010)$ & $(0.0270)$ \\
Sabit & $0.0284^{*}$ & $0.0302^{*}$ \\
Gözlem & $(0.0010)$ & $(0.0000)$ \\
Ülke Sayıst & 792 & 792 \\
$\boldsymbol{R}^{2}$ & 36 & 36 \\
Hausman Testi & 0.87 & 0.77 \\
İst. (Prob.) & 0.7900 & 1.0800 \\
Model & $(0.9402)$ & $(0.8979)$ \\
\hline
\end{tabular}

Model 2

*Not: Parantez içindekiler prob. değerleri; diğerleri ise katsayılardır.

Model 1'de uluslararası turizm harcamalarını temsil eden DLT1 serisi bağımlı; genel küreselleşmeyi temsil eden $D L K O F$ serisi, brüt sabit sermaye oluşumunu temsil eden $D L G F 1$ serisi, reel döviz kurunu temsil eden $D L E X$ serisi ve GSYIH'yi temsil eden $D L G 1$ serisi ise bağımsız serilerdir. Model 1'deki brüt sabit sermaye oluşumunu temsil eden $D L G F 1$ serisi, reel döviz kurunu temsil eden $D L E X$ serisi ve GSYIH'yi temsil eden $D L G 1$ serisi, kontrol değişkenleridir. Modelde HausmanTesti'ne ait prob. değerinin istatistiksel olarak \%5 anlamlılık seviyesinden büyük olduğu ve dolayısıyla da rassal etkiler modelinin geçerli olduğu anlaşılmaktadır. Bu sebeple de Model 1'in tahmininde Genelleştirilmiş En Küçük Kareler Yönteminin rassal etkili modellerde kullanılabilen versiyonu tercih edilmiştir.

Model 1'e ait tahmin sonuçlarında; genel küreselleşmeyi temsil eden DLKOF serisi 1.4680 katsayısı ile istatistiksel olarak \%1 anlamlılık seviyesinde pozitif yönlü olarak, brüt sabit sermaye oluşumunu temsil eden DLGF1 serisi 0.0118 katsayıs1 ile istatistiksel olarak \%1 anlamlılik seviyesinde pozitif yönlü olarak, reel döviz kurunu temsil eden DLEX serisi 0.9056 katsayısı ile istatistiksel olarak \%1 anlaml1lık seviyesinde pozitif yönlü olarak ve GSYİH'yi temsil eden $D L G 1$ serisi ise 0.6064 katsayısı ile istatistiksel olarak \%1 anlamlılık seviyesinde pozitif yönlü olarak; turizm harcamalarını temsil eden DLT1 serisini etkilemektedir. Yani kontrol değişkenlerine ait etkileri bir yana bırakırsak; küreselleşmenin, turizm harcamalarını pozitif yönlü olarak etkilediği görülmektedir.

Model 2'de uluslararası turizm gelirlerini temsil eden DLT3 serisi bağımlı; genel küreselleşmeyi temsil eden $D L K O F$ serisi, brüt sabit sermaye oluşumunu temsil eden $D L G F 1$ serisi, reel döviz kurunu temsil eden $D L E X$ serisi ve GSYİH'yi temsil eden $D L G 1$ serisi ise yine

Turkish Studies - Economy, 15(3) 
bağımsız serilerdir. Brüt sabit sermaye oluşumunu temsil eden $D L G F 1$ serisi, reel döviz kurunu temsil eden DLEX serisi ve GSYIH'yi temsil eden $D L G 1$ serisi, Model 2'ye birer kontrol değişkeni olarak eklenmiştir. Modelde HausmanTesti'ne ait prob. değerinin istatistiksel olarak \%5 anlamlılık seviyesinden büyük olduğu ve dolayısıyla da rassal etkiler modelinin geçerli olduğu anlaşılmaktadır. Bu sebeple de Model 2'nin tahmininde yine Genelleştirilmiş En Küçük Kareler Yönteminin rassal etkili modellerde kullanılabilen versiyonu tercih edilmiştir.

Model 2'ye ait tahmin sonuçlarında; genel küreselleşmeyi temsil eden DLKOF serisi 2.1643 katsayısı ile istatistiksel olarak \%1 anlamlılık seviyesinde pozitif yönlü olarak, brüt sabit sermaye oluşumunu temsil eden DLGF1 serisi 0.0092 katsay1s1 ile istatistiksel olarak \%1 anlamlılık seviyesinde pozitif yönlü olarak, reel döviz kurunu temsil eden DLEX serisi 0.6073 katsayısı ile istatistiksel olarak \%1 anlamlılık seviyesinde pozitif yönlü olarak ve GSYIH'yi temsil eden DLG1 serisi ise 0.4244 katsayıs1 ile istatistiksel olarak \%1 anlamlıl1k seviyesinde pozitif yönlü olarak; turizm gelirlerini temsil eden DLT3 serisini etkilemektedir. Yani kontrol değişkenlerine ait etkileri bir yana bırakırsak; küreselleşmenin, turizm gelirlerini de pozitif yönlü olarak etkilediği görülmektedir.

\section{Sonuç ve Değerlendirme}

Bu çalışmada OECD Ülkelerinde 2000-2018 periyodu için küreselleşmenin, turizm üzerindeki etkisi panel veri analiz yöntemiyle araştırılmıştır. Turizm hem turizm harcamaları hem de turizm gelirleri olmak üzere iki farklı seri ile temsil edilmiştir. Birinci modelde turizm harcamaları, ikinci modelde ise turizm gelirleri bağımlı birer seri olarak tanımlanmıştır.

Çalışmada ilk olarak; kullanılan modellerde olası yatay kesit bağımlılığının tespiti için Peseran CD LM Testine başvurulmuştur. Elde edilen bulgularda her iki model için de prob. değerlerinin istatistiksel olarak $\% 5$ anlamlılı seviyesinden küçük olması, yatay kesit bağımlılığının bulunmadığını ifade eden $\mathrm{H}_{0}$ hipotezinin reddedilerek, yatay kesit bağımlılığının bulunduğunu ifade eden $\mathrm{H}_{1}$ hipotezinin kabul edilmesi gerektiğini ifade etmektedir. Dolayısıyla her iki modelde de yatay kesit bağımlılığının bulunduğu anlaşılmaktadır. Bu nedenle serilere ilişkin durağanlıkların tespitinde, yatay kesit bağımlılığının varlığında bile tutarlı tahminlerde bulunabilen ikinci nesil birim kök testlerinden Pesaran CIPS Birim Kök Testi kullanılmıştır. Birim kök sinamasına ait sonuçlarda, serilerinin tümünün, I(0)'da durağan olmadığı, I(1)'de durağan olduğu anlaşılmış ve seriler, birinci farkları alınarak I(1)'de durağan hale getirilerek, modeller kurulmuştur.

F Testi sonuçlarında her iki modelde de birim etkilere ait $\mathrm{F}$ Testi prob. değerlerinin istatistiksel olarak \%5 anlamlılık seviyesinden düşük olduğu anlaşılmaktadır. Bir diğer deyişle, birim etkilerin bulunmadığını ifade eden $\mathrm{H}_{0}$ hipotezi kabul edilerek, birim etkilerin bulunduğunu ifade eden $\mathrm{H}_{1}$ hipotezi ise reddedilir. Buna karşın her iki modelde zaman etkilere ait $\mathrm{F}$ Testi prob. değerlerinin istatistiksel olarak $\% 5$ anlamlılık seviyesinden düşük olduğu görülmektedir. Yani zaman etkilerin bulunmadığını ifade eden $\mathrm{H}_{0}$ hipotezi reddedilerek, zaman etkilerin bulunduğunu ifade eden $\mathrm{H}_{1}$ hipotezi kabul edilir. Dolayısıyla modellerde birim ve zaman etkilerin birlikte bulunduğu iki yönlü modellerin kullanılabilir olmadığı, tek yönlü zaman etkiler modellerinin geçerli olduğu anlaşılmaktadır.

Model 1'e ait tahmin sonuçlarında; genel küreselleşmeyi temsil eden DLKOF serisi 1.4680 katsayısı ile istatistiksel olarak $\% 1$ anlamlılık seviyesinde pozitif yönlü olarak, brüt sabit sermaye oluşumunu temsil eden DLGF1 serisi 0.0118 katsayıs1 ile istatistiksel olarak \%1 anlamlıl1k seviyesinde pozitif yönlü olarak, reel döviz kurunu temsil eden DLEX serisi 0.9056 katsayısı ile istatistiksel olarak \%1 anlamlılık seviyesinde pozitif yönlü olarak ve GSYİH'yi temsil eden $D L G 1$ serisi ise 0.6064 katsayısı ile istatistiksel olarak \%1 anlamlılık seviyesinde pozitif yönlü olarak; turizm harcamalarını temsil eden DLT1 serisini etkilemektedir. Yani kontrol değişkenlerine ait 
etkileri bir yana bırakırsak; küreselleşmenin, turizm harcamalarını pozitif yönlü olarak etkilediği görülmektedir.

Model 2'ye ait tahmin sonuçlarında ise; genel küreselleşmeyi temsil eden DLKOF serisi 2.1643 katsayısı ile istatistiksel olarak $\% 1$ anlamlılık seviyesinde pozitif yönlü olarak, brüt sabit sermaye oluşumunu temsil eden DLGF1 serisi 0.0092 katsayısı ile istatistiksel olarak \%1 anlamlılık seviyesinde pozitif yönlü olarak, reel döviz kurunu temsil eden $D L E X$ serisi 0.6073 katsayısı ile istatistiksel olarak \%1 anlamlılık seviyesinde pozitif yönlü olarak ve GSYİH'yi temsil eden $D L G 1$ serisi ise 0.4244 katsayısı ile istatistiksel olarak \%1 anlamlılık seviyesinde pozitif yönlü olarak; turizm gelirlerini temsil eden DLT3 serisini etkilemektedir. Yani kontrol değişkenlerine ait etkileri bir yana bırakırsak; küreselleşmenin, turizm gelirlerini de pozitif yönlü olarak etkilediği anlaşılmaktadır.

Çalışmada elde edilen bulgular doğrultusunda küreselleşme faktörlerinde yaşanacak bir iyileşmenin ülkeler açısından turizmin gelişmesine katkı sağlaması beklenmektedir. Bu kapsamda özellikle turizm gelirlerinin artmasının ülke ekonomileri üzerinde beklenen olumlu etkileri düşünüldüğünde küreselleşme endeksinin artırılmasına yönelik politika geliştirilmesi gerekmektedir. Çünkü turizm gelirlerindeki yaşanan artış herhangi bir ülkenin turizm gelişimi için ana hedefidir. Bu doğrultuda sürdürülebilir turizm ve rekabet edebilirliği sağlamak için temel pazar niteliğindeki ülkelerdeki turistlerin eğilimleri ve değişimlerine uygun bir turizm ürünü geliştirmek önem arz etmektedir. Bu nedenle talep odaklı bir yaklaşımla birlikte inovasyonla desteklenen bir turizm ürünü oluşturmaya yönelik turizm stratejilerinin uygulanması gerekmektedir. Bu kapsamda kalite iyileştirme, yenilenme ve ürün farklılaştırılması bu süreçte önemli rol oynamaktadır. $\mathrm{Bu}$ durum rekabet gücünün korunmasına da olumlu katkı sağlayacaktır. Ayrıca turizm ürününde fiyat esnekliklerinin oluşturularak yeni pazar araştırmaları da turizm sektörünün gelişimini pozitif yönde etkileyecektir. Bununla birlikte küreselleşme ve turizm arasındaki ilişkiye yönelik ampirik yönde yapılacak araştırmaların literatürün gelişmesine katkı sağlayacağı düşünülmektedir.

\section{Kaynakça}

Agenor, P. R. (2003). Benefitsand costs of international financial integration: Theory and facts. The World Economy, 26(8),1089-1118. https://doi.org/10.1111/1467-9701.00564

Alagöz, M. \& Erdoğan, S. (2008). İhracat ile turizm gelirlerindeki değişimin cari işlemler dengesi üzerine etkisi. KMU IIIBF Dergisi, 14, 214-227.

Ayaydın, H., Baltacı, N., Pala, F. \& Barut, A. (2019). Türkiye'de turizm, finansal gelişme ve ekonomik büyüme arasındaki ilişki. Global Journal of Economicsand Business Studies, 8 (15), 69-84.

Bahar, O. \& Baldemir, E. (2008). Uluslararası ticaret ile uluslararası turizm arasındaki nedensellik ilişkisi: Türkiye örneği. Dokuz Eylül Üniversitesi Sosyal Bilimler Dergisi, 9(4), 55-66.

Bahar, O. (2007). Küreselleşme sürecinde Türkiye'de turizm sektörüne sağlanan teşvikler. Dokuz Eylül Üniversitesi Sosyal Bilimler Enstitüsü Dergisi, 9(1),61-78.

Bezic, H. \& Radic, M.N. (2017). Tourism foreign direct investment led tourism gross value added: A co-integration and causality analysis of Croatian tourism. Economic ResearchEkonomska Istraživanja, 30(1), 1443-1460. https://doi.org/10.1080/1331677X.2017.1340173

Bozgeyik, Y. \& Eban, F. (2017). Türkiye'de turizm gelirlerinin cari işlemler dengesi üzerindeki etkisi: 2000-2015 dönemine ilişkin ampirik çalışma. The Journal of Social Science, 11, 966-978. 
Buluk, B. \& Özkök, F. (2016). Küreselleşme hareketlerinin turizm endüstrisine etkisi. Akademik Bakış Dergisi,54,37-53.

Bulut, E. (2000). Türk turizminin Dünya'daki yeri ve dış ödemeler bilançosuna etkisi. Gazi Üniversitesi İktisadi ve İdari Bilimler Fakültesi Dergisi, 2(3), 71-86.

Cattaneo, Ol. (2009). Tourism as a strategy to diversify exports: Lessons from mauritius. Richard N., William S., \& Peter W. (Ed.), In breaking in to new markets: emerging lessons for export diversification, World Bank.

Chen, Y. (2017). China's tourism-led foreign direct investment inflows: An empirical study. Modern Economy, 8(1), 8, 39-50.

Cohen, E. (2012). Globalization, global crises and tourism. Tourism Recreation Research, 37(2), 103-111.

Croes, R.R. (2006). A paradigm shift to a new strategy for small island economies: Embracing demand side economics for value enhancement and long term economic stability. Tourism Management, 27, 453-465.

Çeken, H. \& Ateşoğlu, L. (2008). Küreselleşme sürecinde turizm endüstrisinin Avrupa Birliği ve Türkiye ekonomisindeki yeri ve önemi. Gazi Üniversitesi Ticaret ve Turizm Eğitim Fakültesi Dergisi, 1, 136-151.

Çeken, H., Ateşoğlu, L., Dalgın, T. \& Karadağ, L. (2008). Turizm talebine bağlı olarak uluslararası turizm hareketlerindeki gelişmeler. Elektronik Sosyal Bilimler Dergisi, 7(26), 71-85.

Çeken, H., Dalgın, T. \& Karadağ, L. (2009). Küreselleşme ve uluslararası turizm arasındaki ilişki. Muğla Üniversitesi Sosyal Bilimler Enstitüsü Dergisi, 22, 21-36.

Dritsakis, N. (2004). Tourism as a long-run economic growth factor: An empirical investigation for Greece using causality analysis. Tourism Economics, 3, 305-316.

El-Sahli, Z. (2018). The role of inbound tourist flows in promoting exports. The World Economy, 41(5), 1457-1475.

Elias, S. \& Proença, S. (2008). Tourism as an alternativesource of regionalgrowth in Portugal: A Panel Data Analysis. Portuguase Economic Journal, 1, 43-61.

Fayissa, B. (2008). Theimpact of tourism on theeconomicgrowthanddevelopment of Africa. TourismEconomics, 4, 807-818.

Fereidouni, H. G., Al-Mulali, U. \& Najdi, Y. (2014). Globalization indicators-inbound tourism relationship in the MENA Region. Anatolia, 25(3), 364-373. https://doi.org/10.1080/13032917.2014.882849

Fischer, C. \& Gil-Alana, L.A. (2009). The nature of the relationship between international tourism and international trade: The case of German import of Spanish wine. Applied Economics, 41, 1345-59.

Fry, D., Saayman, A. \& Saayman, M. (2010). The Relationship between tourism and trade in South Africa. South AfricanJournal of Economics, 78, 287-306.

Gövdeli, T. (2018). Türkiye'de turizm, ihracatveekonomikbüyümeilişkisi: Maki eşbütünleşmeve Bootstrap nedensellikanalizi. Bingöl Üniversitesi Sosyal Bilimler Enstitüsü Dergisi, 8(16), 571-586.

Gövdeli, T. (2019). The dynamic links between, foreign direct investment, tourism and economic growth in the European. Avrasya Uluslararası Araştırmalar Dergisi, 7(19),407-427. 
Gautam, V. \& KG, S. (2012). An empirical investigation about relationship between international trade and tourist arrival: Evidence from India. Business Excellence and Management, 2(3), 53-62.

Gujarati, D. N. \& Porter, D. C. (2012). Temel Ekonometri. (Çev.) Şenesen Ü. \& Şenesen G. G. Literatür Yayınları

Hausman, J.(1978). Specificationtest in econometrics. Econometrica,46(6),1251-1271.

Hernández-Martín, R. (2007). Tourism events: Impact on imports. International Journal of Event Management Research, 3(1), 15-28.

Hepektan, E. \& Çınar, S. (2010). Turizm sektörünün Türkiye ekonomisi üzerindeki etkileri. Celal Bayar Üniversitesi Sosyal Bilimler Enstitüsü Dergisi, 2, 135-154.

Hociung, I.G. \& Frâncu, L.G. (2012). Globalization - tourism - communication, competitiveness triangle on the market affected by the economic crisis. Theoretical and Applied Economics, 19 (7), 133-146.

ILO (2001). Human resources development, employment and globalization in the hotel, catering and tourism sector. Report for discussion at the tripartite meeting on the human resources development, employment and globalization in the hotel, catering and tourism sector, International Labor Organization Office. https://www.ilo.org/public/libdoc/ilo/2001/101B09_23_engl.pdf

IMF (2000). Globalization: threatoropportunity. A Report bytheStaff of International MonetaryFund. https://www.imf.org/external/np/exr/ib/2000/041200to.htm\#II

Javid, E. \& Katırcıoğlu, S. (2017). The globalization indicators-tourism development nexus: A dynamic Panel-Data Analysis. Asia Pacific Journal of Tourism Research,22(11), 11941205. https://doi.org/10.1080/10941665.2017.1378240

Kadir, N. \&Jusoff, K. (2010). The cointegration and causality tests for tourism and trade in Malaysia. International Journal of Economics and Finance, 2(1), 138-143.

Kanca, C.O. (2015). Turizm gelirleri ve ekonomik büyüme: Türkiye Örneği (1980-2013). Marmara Sosyal Araştırmalar Dergisi, 8, 1-14.

Katırcioglu, S. (2009). Tourism, trade and growth: The case of Cyprus. Applied Economics,41, $2741-2750$

Khan, H., Toh Rex, S. \& Chua L. (2005). Tourism and trade: Cointegration and Granger causality test. Journal of Travel Research,44(2), 171-176.

Khalil, S., Kakar, M. \& Waliullah, K. (2007). Role of tourism in economicgrowth: EmpiricalEvidencefrom Pakistan Economy. The Pakistan Development Review, 4, 985995.

Kızılgöl, Ö. \& Erbaykal, E. (2008). Türkiye'de turizm gelirleri ile ekonomik büyüme ilişkisi: Bir nedensellik analizi. Süleyman Demirel Üniversitesi Iktisadi ve İdari Bilimler Fakültesi Dergisi, 2, 351-60.

Kızılkaya, O. Sofuoğlu, E. \& Karaçor, Z. (2016). Türkiye'de turizm gelirleri ekonomik büyüme ilişkisi: ARDL sınır testi yaklaşımı. Yönetim ve Ekonomi, 23(1), 203-215.

Kulendran, N. \& Wilson, K. (2000). Is there a relationship between international trade and international travel? Applied Economics, 32(8), 1001-1009.

Kuşat, N. (2011). Küreselleşen dünyada turizm sektörü: Bilgi iletişim teknolojileri ve rekabet gücü. Akademik Araştırmalar ve Çalışmalar Dergisi, 3(5), 114-138. 
Luzzi, F. G. \& Fluckiger, Y. (2003). Tourism and international trade: Introduction. Pacific Economic Review, 8(3), 239-243.

Massidda, C. \& Mattana, P. (2013). A SVECM analysis of the relationship between international tourism arrivals, GDP and trade in Italy. Journal of Travel Research,52(1), 93-105.

Mpofu, T. P. (2009). An assessment of theimpact of tourismglobalization in Africa. Journal of Business and Administrative Studies, 1(2), 1-19.

Mustafa, M. H. (2010) Tourismandglobalization in theArabworld. International Journal of Business and Social Science, 1(1), 37-48.

Ongan, S. \& Göçer, İ. (2020). The causal relationships between international trade and international tourism in NAFTA countries: Applications of time and frequency domain approaches. The International Trade Journal, 34(3), 319-338.

Özcan, C. C. (2016). International trade and tourism for mediterranean countries: A Panel causality analysis. Theoretical and Applied Economics, 23(1), 203-212.

Peric, J. \& Radic, M. N. (2016). FDI-led tourism growth hypothesis: empirical evidence from Croatian tourism. European Journal of Tourism, Hospitality and Recreation,7(3), 179-186.

Peseran, M.H. (2004). General diagnostic tests for cross section dependence in panels. IZA Discussion Paper, 1240, 1-39.

Peseran, M.H. (2007). A simple unit root test in the presence of cross-section dependence. Journal ve Applied Econometrics, 22, 265-312.

Rajapakse, R. P. C. R. (2016). The Relationship between Foreign Direct Investment and Tourism Development: Evidence from Sri Lanka. International Journal of Research in Economics and Social Sciences, 6(5), 183-193.

Santana-Gallego, M., Ledesma-Rodriguez, F. \& Perez- Rodriguez, J. V. (2011). Tourism and trade in OECD Countries. A dynamic heterogeneous panel data analysis. Empirical Economics, 41, 533-554.

Shan, J. \& Wilson, K. (2001). Causality between trade and tourism: Empirical evidence from China. Applied Economics Letters, 8, 279-283.

Saraç, T, B., Sofuoğlu, E. \& Kızılkaya, O. (2018). Turizm gelirlerinin hasıla üzerindeki etkisi: Türkiye Örneği. Tapur, T., Avşaroğlu, S., Arslan, E. \&Kılınç, M. (Ed.), Sosyal ve Beşeri Bilimler Araştırmaları. Çizgi Kitabevi

Sarmidi, T. \& Salleh, N. H. (2010). Dynamic inter-relationship between trade, economic growth and tourism in Malaysia. MPRA Paper No.21056.

Satrovic, E. \& Muslija, A. (2019). Causality relationship between foreign direct investment and tourism. Uluslararası İktisadi ve İdari Incelemeler Dergisi, 22, 65-76.

Woodlridge, J. (2013). Ekonometriye Giriş. (Çev.) Çağlayan, E. Nobel Akademi Yayıncılık.

Yapar Saçık, S., Akar, G., \& Gülmez, Z. (2019). Turizm gelirlerinin cari işlemler dengesi üzerindeki etkisi: Türkiye örneği. Selçuk Üniversitesi Sosyal Bilimler Enstitüsü Dergisi, 42, 303-316.

Yazdi, S. K., Salehi, K. H. \& Soheilzad, M. (2017). The relationship between tourism, foreign direct investment and economic growth: Evidence From Iran. Current Issues in Tourism, 20(1), 15-26. 
Yerdelen Tatoğlu, F. (2018). Panel Veri Ekonometrisi. Beta Yayınları.

Yu-Chi, S. \& Lin, H.P. (2018). Causality relationship between tourism, foreign direct investment and economic growth in Taiwan. Asian Journal of Economic Modelling, 6(3), 287-293. 